\title{
The challenge of removal of sepsis markers by continuous hemofiltration
}

\author{
Patrick M. Honore ${ }^{1 *}$, David De Bels ${ }^{1}$, Rachid Attou', Sebastien Redant ${ }^{1}$ and Kianoush Kashani ${ }^{2}$ \\ This comment refers to the article available at https://doi.org/10.1186/s13054-018-2001-5.
}

We enthusiastically read the paper by Elke et al. showing that mid-regional pro-adrenomedullin (MR-proADM) performance in the determination of the severity of illness and treatment response in sepsis to be more accurate in comparison with the established biomarkers such as C-reactive protein (CRP) and procalcitonin (PCT) [1]. We also like to highlight the validity of CRP, PCT, and MR-proADM measurements during continuous renal replacement therapy (CRRT). As Elke et al. indicated, CRRT is extensively used in sepsis $(20.5 \%$ in the survivors and $58.1 \%$ in non-survivors). Acute phase reactant proteins (CRP and PCT) are effectively cleared by CRRT. CRP is predominantly present as a monomer (mCRP) in the blood [2] and is removed by all CRRT modalities given its low molecular weight $(22-25 \mathrm{kDa})$ [2]. PCT is shown to be eliminated by convection, as well [3]. Also, dialysis membrane absorbs a substantial proportion of mCRP and PCT [3, 4]. As highly adsorptive dialysis membranes are increasingly used in CRRT worldwide, elimination of mCRP and PCT could be significantly accentuated. Hence, among CRRT patients, plasma levels of both biomarkers could be falsely low. On the other hand, the MR-proADM molecular weight (MW) is between 4 and $5.5 \mathrm{kDa}$, and, therefore, it may also be removed by CRRT. Indeed, Mueller et al. showed a significant decrease in MR-proADM (45-65\%) if a high-flux membrane was used (with a cut-off of 35,000 Da) [4]. This cut-off is similar to what is used in contemporary CRRT membranes [5]. In Elke et al. study, $20.5 \%$ of the survivors and $58.1 \%$ of the non-survivors received CRRT, and the value of MR-proADM was 4.0 and $8.2 \mathrm{nmol} / \mathrm{L}$ in each group $(P$ value $<.001)$, respectively. As the average MR-proADM, CRP, and PCT levels in each group could have been impacted by differences

\footnotetext{
* Correspondence: Patrick.Honore@CHU-Brugmann.be

${ }^{1}$ ICU Department, Centre Hospitalier Universitaire Brugmann, Place Van Gehuchtenplein,4, 1020 Brussels, Belgium

Full list of author information is available at the end of the article
}

in the CRRT prevalence, we recommend a sensitivity analysis to be done after the exclusion of CRRT patients to clarify the performance of these biomarkers when they are not artificially removed by an extracorporeal purification technique. At this point, there is no biomarker proven to reliably predict sepsis or infection among CRRT patients. Hence, the odyssey continues!

\section{Abbreviations \\ CRP: C-reactive protein; CRRT: Continuous renal replacement therapy; mCRP: Monomeric CRP; MR-proADM: Mid-regional pro-adrenomodullin; MW: Molecular weight; PCT: Procalcitonin}

\author{
Acknowledgements \\ None. \\ Funding \\ None. \\ Availability of data and materials \\ Not applicable.
}

\section{Authors' contributions}

$\mathrm{PMH}$ and $\mathrm{KK}$ designed the paper. All authors participated in drafting and reviewing. All authors read and approved the final version of the manuscript.

Ethics approval and consent to participate

Not applicable.

\section{Consent for publication \\ Not applicable.}

\section{Competing interests}

The authors declare that they have no competing interests.

\section{Publisher's Note}

Springer Nature remains neutral with regard to jurisdictional claims in published maps and institutional affiliations.

\section{Author details}

${ }^{1}$ ICU Department, Centre Hospitalier Universitaire Brugmann, Place Van Gehuchtenplein,4, 1020 Brussels, Belgium. ²Division of Nephrology and Hypertension, Division of Pulmonary and Critical Care Medicine, Department of Medicine, Mayo Clinic, Rochester, USA. 
Received: 13 April 2019 Accepted: 1 May 2019

Published online: 15 May 2019

\section{References}

1. Elke G, Bloos F, Wilson DC, Brunkhorst FM, Briegel J, Reinhart K, et al. The use of mid-regional proadrenomedullin to identify disease severity and treatment response to sepsis - a secondary analysis of a large randomised controlled trial. Crit Care. 2018;22:79.

2. Taylor KE, van den Berg CW. Structural and functional comparison of native pentameric, denatured monomeric and biotinylated C-reactive protein. Immunology. 2007;120:404-11.

3. Dahaba AA, Elawady GA, Rehak PH, List WF. Procalcitonin and proinflammatory cytokine clearance during continuous venovenous haemofiltration in septic patients. Anaesth Intensive Care. 2002;30:269-74.

4. Mueller T, Gegenhuber A, Kronabethleitner G, Leitner I, Haltmayer M,

Dieplinger B. Plasma concentrations of novel cardiac biomarkers before and after hemodialysis session. Clin Biochem. 2015;48:1163-6.

5. Honore PM, Spapen HD. What a clinician should know about a renal replacement membrane? J Transl Int Med. 2018;6(2):62-5. https://doi.org/10. 2478/jtim-2018-0016 eCollection 2018 Jun. 